\title{
MENINGKATKAN KEMAMPUAN MENULIS CERPEN SISWA SMP NEGERI 1 DRIYOREJO MENGGUNAKAN MEDIA KOMIK PADA VIDEO POWTOON
}

\author{
Diana Fatmawati, Retno Danu Rusmawati \\ Pendidikan Bahasa dan Sastra Indonesia, Fakultas Keguruan dan Ilmu Pendidikan, \\ Universitas PGRI Adi Buana Surabaya \\ Baik_diana@yahoo.com, Retnodanu@ymail.com
}

\begin{abstract}
This research is motivated by the low ability of grade 7 A students of SMP Negeri 1 Driyorejo in learning Indonesian, especially in the Basic Competence of "writing short stories". This study uses video powtoon as a solution to improve short story writing skills. Powtoon videos can also be used for various learning fields other than Indonesian. In this study, the data collection techniques used by the author include interview techniques, documentation techniques, observation techniques, questionnaire or test techniques. Data analysis in this study used a qualitative descriptive technique. The population in this study were students of SMP Negeri 1 Driyorejo and the sample consisted of 9 students. The results of the acquisition of the ability to write short stories for the seventh grade students of SMP Negeri 1 Driyorejo in the first cycle were below average, while the scores in the second cycle were above the average. The results of this study indicate that the ability to write short stories for seventh grade students of SMP Negri 1 Driyorejo can improve after applying comics media to video powtoon. Based on the presentation and the results of the discussion, educators can use video powtoon media to improve the ability to write short stories for class VII students of SMP Negeri 1 Driyorejo in particular and others in general.
\end{abstract}

Keywords: students, media, ability, writing.

\section{PENDAHULUAN}

Dalam pembelajaran, materi bahasa Indonesia merupakan salah satu tugas bagi guru untuk merencanakan dan menerapkan strategi yang tepat agar siswa termotivasi dalam belajar. Hal tersebut banyak dipengaruhi oleh berbagai faktor. Salah satunya diduga bahwa media merupakan salah satu faktor penyebabnya. Maka dari itu, penulis berpikir untuk menerapkan kepada siswa melalui media pembelajaran yang lebih kreatif dengan asumsi bahwa pembelajaran akan lebih efektif dan menarik. Berdasarkan hasil pembicaraan peneliti dengan guru mata pelajaran Bahasa Indonesia SMP Negeri 1 Driyorejo, diperoleh informasi bahwa meskipun guru sudah berusaha melakukan pembelajaran PAKEM, dalam pelaksanaan pembelajaran masih banyak permasalahan yang dihadapi dalam pembelajaran bahasa Indonesia.

Salah satunya adalah berkaitan dengan kemampuan siswa dalam menulis cerpen. Hasil observasi awal dan informasi dari guru menunjukkan bahwa kemampuan menulis cerpen siswa masih rendah. Dari dokumentasi nilai yang 
dimiliki guru, diketahui bahwa rerata tingkat kemampuan menulis cerpen siswa masih dibawah rata-rata dalam menulis cerpen dengan baik.

Untuk itu penulis menggunakan media sebagai strategi yang tepat agar siswa termotivasi dalam menulis cerpen. Media tersebut berupa komik pada video powtoon. Di dalam video tersebut terdapat gambar-gambar komik kartun berangkai yang menarik dengan disertai langkah-langkah atau cara menuangkannya ke dalam sebuah cerita. Sehingga membuat siswa memiliki keinginan untuk memperhatikan rangkaian gambar tersebut dan memahaminya.

Penulis menggunakan media komik ini karena pada umumnya siswa SMP kelas 1 masih sangat awal dan cenderung lebih suka pada film-film atau gambar-gambar yang berupa kartun atau animasi, sehingga akan lebih efektif bagi siswa ketika menggunakan media komik tersebut dalam pembelajaran menulis cerpen. Media komik pada video powtoon sangatlah sederhana. Gambar kartunnya langsung menunjukkan konflik dan alur ceritanya langsung berakhir, jadi siswa tidak akan merasa bosan dan tentunya tidak akan membutuhkan waktu yang lama untuk menuangkannya ke dalam cerpen.

Dari sinilah penulis berpikir untuk menggunakan media komik pada video powtoon sebagai media yang efektif untuk pembelajaran menulis cerpen. karena alur cerita didalamnya sangat sederhana begitu juga dengan dialognya. Sehingga siswa akan lebih mudah mencerna setting dan perwatakan tokoh yang ada dalam cerita gambar tersebut.

Dalam penelitian ini bermaksud untuk meningkatkan kemampuan menulis cerpen siswa SMP Negri 1 Driyorejo melalui penggunakan media komik pada video powtoon. Dengan peningkatan kemampuan siswa dalam menulis cerpen, akan sekaligus meambah pengetahuan juga pengalaman siswa dalam pengolahan kata, struktur cerpen, unsur-unsur yang digunakan dalam menulis cerpen, dan pemahaman mengenai ejaan dan tanda baca dalam menulis cerpen

Selain itu guru juga tidak terlalu kesulitan untuk menjelaskan materi menulis cerpen kepada siswa karena dalam video powtoon tersebut sudah menjelaskan semua materi dalam menulis cerpen yang menggunakan media komik.

Media adalah perantara atau pengantar pesan dari pengirim ke penerima pesan (Sadiman dkk, 1986: 6). Menurut Hamalik (1986: 23) menyimpulkan bahwa media pendidikan adalah alat atau metode dan teknik yang digunakan dalam rangka lebih mengefektifkan komunikasi dan interaksi antara guru dan siswa dalam proses pendidikan dan pengajaran disekolah. Beberapa keterangan tersebut dapat disimpulkan bahwa media pembelajaran adalah bagian yang tidak terpisahkan dari proses belajar mengajar demi tercapainya tujuan pendidikan pada umumnya dan tujuan pembelajaran di sekolah pada khususnya. Selain itu media merupakan suatu alat bantu yang sangat penting sebagai perantara untuk menyampaikan pembelajaran secara efektif terhadap siswa di sekolah.

Menurut Sudjana \& Rivai (2011.1332 : 64) komik dapat didefinisikan sebagai suatu bentuk kartun yang mengungkapkan karakter dan memerankan suatu cerita dalam urutan yang erat dihubungkan dengan gambar dan dirancang untuk memberikan hiburan kepada para pembaca. Komik bersifat humor, sedangkan sumbangan yang paling unik dan berarti dari kartun pada bidang masalah-masalah politik dan sosial. 
Komik memusatkan perhatian di sekitar rakyat. Cerita-ceritanya mengenai diri pribadi sehingga pembaca dapat segera mengidentifikasikan dirinya melalui perasaan serta tindakan dari perwatakan-perwatakan dari tokoh utamanya. Cerita-ceritanya ringkas dan menarik perhatian, dilengkapidengan aksi,bahkan dalam lembaran surat kabardan buku-buku, komik dibuat

lebih hidup, serta diolah dengan pemakaian warna-warna utama secara bebas.

Video adalah gambar-gambar suatu objek yang bergerak bersama-sama dengan suara alamiah atau suara yang sesuai, Arsyad (2010: 49). Kemampuan video melukiskan gambar hidup dan suar memberinya daya tarik tersendiri. Media ini pada umumnya digunakan untuk tujuan-tujuan hiburan, dokumentasi, dan pendidikan. Karena pada media ini dapat menyajikan informasi, memaparkan proses, menjelaskan konsep-konsep yang rumit, mengajarkan keterampilan, menyingkat atau memperpanjang waktu, dan mempngaruhi sikap, Arsyad (2010: 49).

Powtoon adalah aplikasi berbasis web yang memungkinkan untuk membuat presentasi yang informatif, berwarna, dan animatif. Powtoon dikembangkan oleh perusahaan Powtoon Ltd yang berbasis di Inggris. Aplikasi ini sangat mudah digunakan, pengguna hanya perlu melakukan click and drop. Bermacam jenis teks, grafik, video dan flash telah tersedia di dalamnya. Oleh karena itu, video powtoon akan lebih memudahkan pendidik untuk menerapkan media komik kepada siswa dalam meningkatkan menulis cerpen. Siswa akan diajak bermain di dalamnya, imajinasi siswa akan muncul dengan sendirinya, dan pembelajaran akan berjalan dengan sangat menyenangkan dengan menampilkan video powtoon sebagai penerapan media komik.

Menulis adalah suatu kegiatan yang produktif dan ekspresif, Tarigan, (1994: 3). Dalam kehidupan modern ini, jelas bahwa keterampilan menulis sangat dibutuhkan. Kiranya tidaklah terlalu berlebihan bila kita katakan bahwa keterampilan menulis merupakan suatu ciri dari orang yang terpelajar atau bangsa yang terpelajar.

Sehubungan dengan hal ini, ada penulis yang mengatakan bahwa menulis dipergunakan untuk melaporkan / memberitahukan, dan mempengaruhi. Tujuan seperti itu hanya dapat dicapai dengan baik oleh orang-orang yang dapat menyusun pikirannya dan mengutarakannya dengan jelas. Kejelasan ini bergantung pada pikiran, organisasi, pemakaian kata-kata, dan struktur kalimat Morsey (dalam Tarigan, 1994: 4).

\section{METODE PENELITIAN}

Subjek penelitian ini adalah siswa SMPN 1 Driyorejo kelas VII A semester ganjil tahun pelajaran 2014/2015. Jumlah siswa sebanyak 34 siswa. Latar penelitian ini dilaksanakan di SMPN 1 Driyorejo di kelas VII A yang terletak di Jl. Tanaru Kota Gresik. Penelitian pada siklus I ini dilakukan pada hari Rabu tanggal 12 tahun 2014, dan pada siklus II dilakukan pada hari senin tanggal 16 tahun 2014. Pemilihan tempat penelitian ini bertujuan untuk meningkatkan keterampilan menulis cerpen siswa secara kreatif dan terampil pada sekolah tersebut.

Penelitian ini merupakan rancangan Penelitian Tindakan Kelas karena gejala yang diamati dibuat secara sengaja untuk mengetahui adanya peningkatan 
hasil belajar Bahasa Indonesia melalui media komik pada video powtoon. Menurut Yuyun (dalam Muslich, 1830 : 40) mengemukakan bahwa proses pelaksanaan tindakan dilaksanakan secara bertahap sampai penelitian ini berhasil. Prosedur tindakan dimulai dari beberapa siklus anatara lain siklus I dan siklus II.

Pembobotan data yang dilakukan dengan memberikan skor pada masingmasing hasil tes siswa dalam membuat karangan didasarkan pada aspek-aspek yang meliputi:

1. Keutuhan

2. Kepaduan

3. Ejaan dan tanda baca

Keutuhan :

$1=$ Penceritaan gambar tidak urut sesuai dengan rangkaian gambar.

2 = Penceritaan gambar kurang urut antara satu dengan yang lain.

3= Gambar diceritakan secara urut atau kronologis. Berdasarkan rangkaian gambar sehingga menjadi karangan yang utuh.

Kepaduan :

1 = Antar kalimat tidak dihubungkan dengan kata sambung / pengulangan kata kunci / rujukan yang sesuai.

$2=$ Antar kalimat dihubungkan dengan kata sambung / pengulangan kata kunci/rujukan, namun ada beberapa kata hubung yang tidak sesuai dengan penggunaannya.

3 = Antar kalimat dihubungkan dengan kata sambung/pengulangan kata kunci/rujukan yang sesuai.

Ejaan dan tanda baca :

$1=$ Terdapat banyak (lebih dari 3) kesalahan struktur kalimat, penggunaan ejaan dan tanda baca.

2 = Kesalahan struktur kalimat, penggunaan ejaan dan tanda baca.

3 = Tidak terdapat kesalahan struktur kalimat, penggunaan ejaan dan tanda baca. Terdapat beberapa (tidak lebih dari 3)

Berikut cara untuk mengetahui hasil belajar siswa melalui penggunaan media komik pada mata pelajaran menulis cerpen dengan menggunakan rumusrumus berikut :

$$
\text { Nilai }=\frac{\text { Skor yang diperoleh }}{\text { Skor maksimal }} \times 100
$$

\begin{tabular}{|l|l|l|l|}
\hline $\begin{array}{l}\text { Taraf penguasaan atau kemampuan } \\
(\%)\end{array}$ & kualifikasi & $\begin{array}{l}\text { Nilai } \\
\text { Angka }\end{array}$ & Keterangan \\
\hline $77,8 \%-100 \%$ & $\begin{array}{l}\text { Sangat } \\
\text { Baik }\end{array}$ & $7-9$ & Berhasil \\
\hline $55,6 \%-77,7 \%$ & Baik & $5-7$ & $\begin{array}{l}\text { Kurang } \\
\text { berhasil }\end{array}$ \\
\hline $05,0 \%-55,5 \%$ & kurang & $0-5$ & Tidak berhasil \\
\hline
\end{tabular}




\section{HASIL PENELITIAN}

Setelah dilaksanakannya kegiatan pembelajaran pada siklus I dengan uji tes menulis cerpen tersebut, diketahui bahwa dari 34 siswa yang diteliti ternyata terdapat 9 siswa yang belum memenuhi tiga aspek dalam kemampuan menulis cerpen. Nilai yang diperoleh 9 siswa tersebut dalam menulis cerpen pada siklus I sangat jauh dibawah rata-rata. Sedangkan nilai yang harus diperoleh minimal 7 , seperti pada tabel di bawah ini:

Berikut data tabel 9 siswa yang mendapat nilai dibawah rata-rata dalam menulis cerpen pada siklusI:

\begin{tabular}{|c|c|c|c|c|c|c|}
\hline \multirow[t]{3}{*}{$\mathrm{NO}$} & \multirow[t]{3}{*}{ NAMA } & \multicolumn{3}{|c|}{ ASPEK YANG DINILAI } & \multirow[t]{3}{*}{ SKOR } & \multirow[t]{3}{*}{ NILAI } \\
\hline & & Keutuhan & Kepaduan & $\begin{array}{l}\text { Ejaan dan tanda } \\
\text { baca }\end{array}$ & & \\
\hline & & $1-3$ & $1-3$ & $1-3$ & & \\
\hline 1. & Adisti & 3 & 2 & 2 & 7 & 77,7 \\
\hline 2. & Ajeng & 2 & 3 & 2 & 7 & 77,7 \\
\hline 3. & Alfi & 2 & 2 & 3 & 7 & 77,7 \\
\hline 4. & Diva & 2 & 2 & 3 & 7 & 77,7 \\
\hline 5. & Anggie & 2 & 3 & 3 & 8 & 88,8 \\
\hline 6. & Ardelia & 1 & 2 & 1 & 4 & 44,4 \\
\hline 7. & Arum & 2 & 1 & 2 & 5 & 55,5 \\
\hline 8. & adam & 2 & 3 & 3 & 8 & 88,8 \\
\hline 9. & Chusnul & 3 & 3 & 3 & 9 & 100 \\
\hline 10. & Deanty & 2 & 2 & 3 & 7 & 77,7 \\
\hline 11. & Ela & 2 & 1 & 2 & 5 & 55,5 \\
\hline 12. & Fadhilah & 2 & 2 & 3 & 7 & 77,7 \\
\hline 13. & Vevernova & 3 & 3 & 3 & 9 & 100 \\
\hline 14. & Happy & 1 & 2 & 1 & 4 & 44,4 \\
\hline 15. & Hilda & 2 & 3 & 2 & 7 & 77,7 \\
\hline 16. & Nafa & 2 & 2 & 3 & 7 & 77,7 \\
\hline 17. & Kunthi & 1 & 2 & 1 & 4 & 44,4 \\
\hline 18. & Habibul & 2 & 3 & 2 & 7 & 77,7 \\
\hline 19. & Mayawati & 1 & 2 & 1 & 4 & 44,4 \\
\hline 20. & Miladatul & 2 & 3 & 3 & 8 & 88,8 \\
\hline 21. & Risky & 2 & 1 & 2 & 5 & 55,5 \\
\hline 22. & Febrianto & 1 & 2 & 1 & 4 & 44,4 \\
\hline 23. & Muthiara & 2 & 2 & 3 & 7 & 77,7 \\
\hline 24. & Ni putu & 2 & 3 & 3 & 8 & 88,8 \\
\hline 25. & Nurhidayah & 3 & 3 & 3 & 9 & 100 \\
\hline 26. & Oktavia & 2 & 3 & 2 & 7 & 77,7 \\
\hline 27. & Andika & 2 & 3 & 2 & 7 & 77,7 \\
\hline 28. & Silvia & 1 & 3 & 3 & 7 & 77,7 \\
\hline 29. & Syahani & 2 & 2 & 3 & 7 & 77,7 \\
\hline 30. & Taufiq & 1 & 2 & 1 & 4 & 44,4 \\
\hline
\end{tabular}




\begin{tabular}{|l|l|l|l|l|l|l|}
\hline 31. & Tiffani & 2 & 2 & 3 & 7 & 77,7 \\
\hline 32. & Valent & 2 & 2 & 3 & 7 & 77,7 \\
\hline 33. & Via & 2 & 3 & 2 & 7 & 77,7 \\
\hline 34. & yoga & 2 & 3 & 3 & 8 & 88,8 \\
\hline
\end{tabular}

Beberapa aspek yang harus diperbaiki berdasarkan hasil evaluasi dan refleksi yaitu:

1. Siswa kurang mampu dalam menuangkan idenya ke dalam bentuk tulisan berdasarkan gambar pada komik yang telah diberikan.

2. Siswa kurang mampu menggunakan unsur kebahasaan untuk memadukan antar kalimat yang menceritakan gambar satu dengan gambar dua.

3. Siswa kurang mampu menggunakan bahasa, ejaan, dan tanda baca yang sesuai.

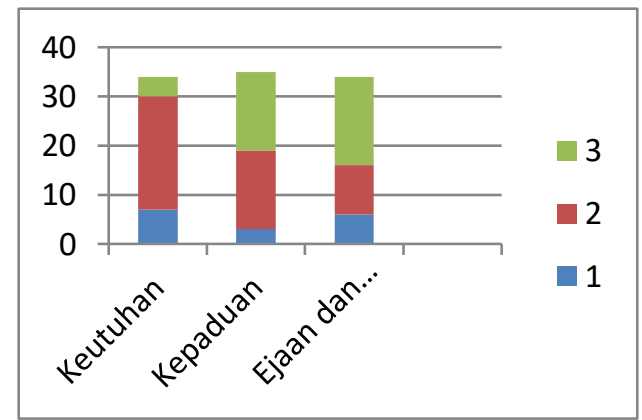

Berdasarkan grafik di atas, dapat diketahui bahwa pemerolehan nilai dari tiga aspek tersebut banyak yang mendapatkan nilai 3 dan 2, tetapi masih ada sebagian siswa yang mendapat nilai 1 .

Maka dari itu peneliti memutuskan untuk melanjutkan penelitian dengan mengadakan siklus II. Pada siklus II ini peneliti mencoba untuk menggunakan media komik dengan 2 video powtoon sebagai alat bantu untuk lebih memudahkan dalam menjelaskan materi menulis cerpen kepada siswa kelas 7 SMP Negeri 1 Driyorejo.

Peneliti bermaksud menampilkan contoh komik kartun pada video powtoon yang pertama dan menampilkan hasil penuangan dari komik menjadi sebuah cerita pada video powtoon yang ke dua,dengan begitu akan mempermudah siswa untuk memahami dan merespon secara baik. Karena kedua video tersebut berisikan informasi untuk menjelaskan mengenai pengartian cerpen fabel, ciri-ciri cerpen fabel, langkah-langkah menulis cerpen, pengguna'an unsur kebahasaan dalam menulis cerpen hingga menuangkan dari sebuah gambar menjadi sebuah 
cerita pendek secara langsung. Sehingga peneliti tidak terlalu menghabiskan waktu lama dalam menjelaskan materi menulis cerpen.

Data hasil pengamatan dari evaluasi yang sudah dilakukan, ternyata telah terjadi perubahan dalam pemerolehan nilai oleh 9 siswa tersebut. Nilai yang diperoleh 9 siswa pada siklus II ini sudah memenuhi kriteria pencapaian tiga aspekyang sudah ditentukan dalam menulis cerpen menggunakan media komik pada video powtoon. Data tersebut dapat peneliti sajikan pada tabel sebagai berikut:

\begin{tabular}{|l|l|l|l|l|l|l|}
\hline \multirow{2}{*}{ NO } & \multirow{2}{*}{ NAMA } & \multicolumn{2}{|l|}{ ASPEK YANG DINILAI } & SKOR & NILAI \\
\cline { 3 - 6 } & & Keutuhan & Kepaduan & Ejaan dan tanda baca & & \\
\cline { 3 - 6 } & & $1-3$ & $1-3$ & $1-3$ & & \\
\hline 1 & Ardelia & 3 & 3 & 3 & 9 & 100 \\
\hline 2 & Mayawati & 3 & 3 & 3 & 9 & 100 \\
\hline 3 & Febrianto & 3 & 3 & 3 & 9 & 100 \\
\hline 4 & Arum & 3 & 3 & 2 & 8 & 89 \\
\hline 5 & Happy & 3 & 3 & 2 & 8 & 89 \\
\hline 6 & Taufiq & 3 & 3 & 2 & 8 & 89 \\
\hline 7 & Ela & 3 & 2 & 2 & 7 & 78 \\
\hline 8 & Kunthi & 3 & 2 & 2 & 7 & 78 \\
\hline 9 & Risky & 3 & 2 & 2 & 7 & 78 \\
\hline
\end{tabular}

Hasil nilai yang didapat, diketahui kemampuan siswa pada tahap pelaksanaan pembelajaran menulis cerpen menggunakan media komik pada video powtoon telah berhasil meningkat. Nilai yang diperoleh 9 siswa diatas rata-rata. Pada siklus II ini menunjukkan bahwa terjadi kenaikan pemerolehan nilai.

Di samping itu, hasil presentase keberhasilan siswa secara umum pada pembelajaran menulis cerpen dengan menggunakan media komik pada video powtoon adalah jumlah skor minimal 7 dibagi skor tertinggi 9 dan dikalikan $100 \%$.

Dari hasil tersebut maka dapat diketahui tingkat keberhasilan siswa dalam menulis cerpen. Apabila siswa memenuhi kriteria penyekoran minimal 7 lebih dari $70 \%$, maka dinyatakan berhasil

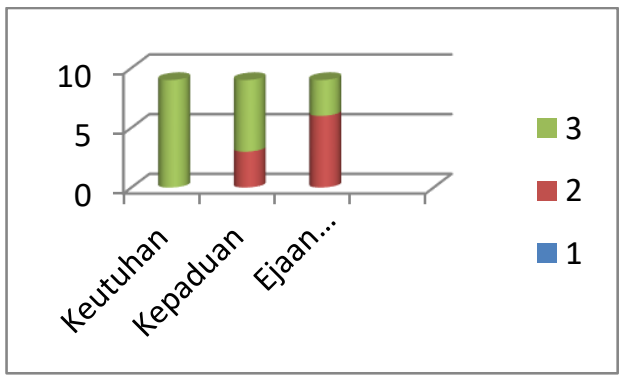

Setelah pengamatan selesai dilakukan, kemudian peneliti bersama teman sejawat melakukan kegiatan refleksi pada setiap akhir tindakan. Peneliti bersama teman sejawat melakukan analisis dan refleksi hasil pembelajaran yang telah dilakukan. Berdasarkan hasil analisis tindakan II diketahui bahwa kemampuan 
siswa lebih meningkat dari tindakan I. Hasil analisis tindakan II diketahui sebagai berikut:

1) Siswa mampu menceritakan rangkaian gambar secara urut.

2) Antar kalimat yang menceritakan gambar saling berhubungan.

3) Siswa mampu menuliskan ejaan dan tanda baca dengan baik dan benar.

\section{SIMPULAN}

Berdasarkan haril analisis, kemampuan menulis cerpen siswa kelas 7 A SMP Negri 1 Driyorejo dapat meningkat dengan menggunakan media komik pada video powtoon. Hal ini dapat dilihat melalui pemberian tes kognitif dari siklus I dan siklus II dengan rumusan skor minimal 7 dibagi skor maksimal 9 dikali 100\%.

\section{SARAN}

Penyajian saran ini, penulis maksudkan agar dapat digunakan untuk meningkatkan kemampuan menulis cerpen siswa SMP/SMA. Khususnya siswa SMP Negri 1 Driyorejo. Berikut saran penulis:

1. Siswa

Media komik pada video powtoon dapat melatih kemampuan siswa dalam menulis cerpen. tidak hanya itu, media ini dapat membantu siswa dalam berpikir kreatif dalam menuangkan ide-ide/ imajinasinya dalam membuat sebuah karangan.

2. Guru

Media komik pada video powtoon akan sangat membantu para guru dalam proses pembelajaran bahasa Indonesia. Karna di dalam video ini tidak hanya untuk materi menulis cerpen saja, bahkan untuk materi pembelajaran bahasa Indonesia yang lain-pun bisa mengguanakan video powtoon agar lebih menarik untuk memancing respon siswa.

3. Dunia Pendidikan

Media komik pada video powtoon ini dapat dijadikan sebagai acuan atau pedoman dalam pembelajaran agar dapat memperoleh hasil pembelajaran secara optimal.

\section{DAFTAR PUSTAKA}

Arsyad, A. 2010. Media Pembelajaran. Jakarta: Rajawali Pers

Basir, U. 2011. Keterampilan Menulis. Surabaya: CV Bintang

Budiyono, S. C. dkk. 2012. Pedoman Penulisan Skripsi dan Artikel Ilmiah. Jakarta: Politeknik Negeri Media Kreatif

Zabadi, F. dkk. 2013. Bahasa Indonesia Wahana Pengetahuan Surabaya: FKIP Adibuana

Fachrurrazi, A. dkk. 2014. Pedoman Program Pengalaman Lapangan (Untuk Program Studi Jenjang S1). Surabaya: FKIP Adibuana

Hamalik, O. 1986. Media Pendidikan. Bandung: Alumni

Kasnadi dan Sutejo. 2010. Kajian Prosa. Yogyakarta: Terakata

Munadi, Y. 2010. Media Pembelajaran (Sebuah Pendekatan Baru). Jakarta: GP Press

Muslich, M. 2009. Melaksanakan PTK(Penelitian Tindakan Kelas) Itu Mudah. Jakarta: PT Bumi Aksara 
Sadiman, A. S dkk. 1986. Media Pendidikan Pengertian, Pengembangan, dan Pemanfaatannya. Jakarta: Rajawali Pers

Sudjana, N dan Rivai, A. 2011.1332. Media Pembelajaran Penggunaan dan Pembuatannya. Bandung: Sinar Baru Algensindo Bandung

Tarigan, H. G. 2008. Menulis Sebagai Suatu Keterampilan Berbahasa. Bandung: Angkasa Bandung

http://digilib.unimed.ac.id/pemanfaatan-media-komik-untuk-meningkatkan-kemampuanmenulis-cerpen-siswa-kelas-X-sma-negeri-2-kabanjahe-30209.html

www.teknologi.co/1496/dengan-powtoon-presentasi-anda-lebih-menarik/

http://www.youtube.com/watch?v=4XOzjP039MQ

www.youtube.com/watch?v=t5tyZGPfVgM

http://www.google.co.id/search?site=\&source=hp\&ei=gohiVNP5JlaOuATf64FY\&q=ga mbar+komik+fabel\&oq=gambar+komik+fabel $+\& g s$ l=mobile-gwshp.12...14397.6609.0.14576.19.18.0.1.1.0.1464.12237.2-

2j3j2j4j2j5.18.0....0...1c.1.58.mobile-gws-hh..5.14.10705.3.h-1AiLi8dTY\#facrc= 